\title{
A cross-cultural relationship
}

\section{The Literary Animal: Evolution and the Nature of Narrative \\ edited by Jonathan Gottschall \& David Sloan Wilson \\ Northwestern University Press: 2005. \\ 375 pp. $\$ 79.95$ (hbk), \$29.95 (pbk)}

\section{Rebecca Goldstein}

Like certain partners in long-term marriages, the arts and sciences have often got along best by agreeing to ignore one another. When they do engage, uncomplimentary comparisons are hurled, leaving one side or the other, or more likely both, feeling misunderstood and unappreciated, unable to do better than lash out in impotent resentment: "You'll never understand me."

But lately these two have been getting on rather better. A significant number of novelists, playwrights and film-makers have turned to the sciences for themes and characters, exploring questions ranging from quantum mechanics to neural networks in ways that not only do justice to the ideas, but also to the passions of those who pursue them. Likewise, a small cadre of scientists have begun to take the arts seriously, looking to them for important questions and data. Such heroic attempts to breach the gap in communication between the two progenitors of our culture are certainly an encouraging sign.

It has been primarily through the emerging field of evolutionary psychology that the arts have come to the respectful attention of the sciences. Itself undergoing an evolution from what had sometimes seemed to be 'just so' hypotheses to a refined theory with explanatory muscle, evolutionary psychology offers the means

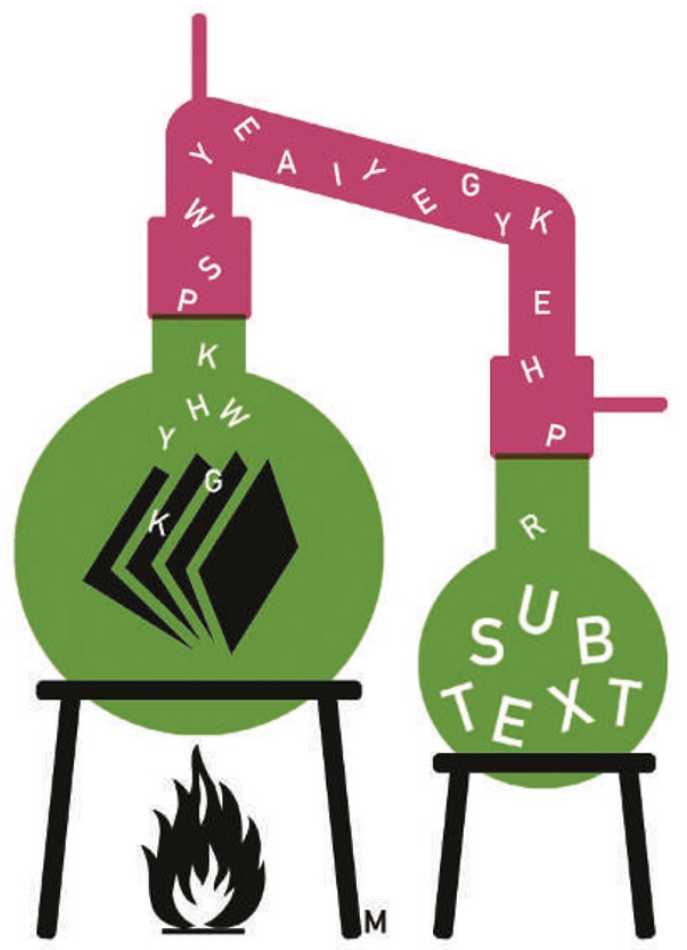

of bringing together the arts and sciences in a mutually reaffirming relationship: each gives the other a means of gaining insight into itself, with neither feeling slighted or outsmarted.

The promise of the evolutionary approach is admirably demonstrated in The Literary Animal, a collection of essays penned by contributors from both sides of the divide. The book provides the exhilarating sense of witnessing something new taking shape on the intellectual horizon, a 'proto-paradigm' that, although grounded, is not yet set in stone, with big questions still being debated.

The Literary Animal focuses on just the narrative arts, novels and drama, a sub-genre of the meeting of the arts and sciences that has been dubbed 'literary darwinism'. One of the basic questions is whether literature, of all the art forms, presents a unique set of issues for evolutionary psychology. The very existence of this book implies that it does, although it is not obvious that all the contributors would agree.

The attention that evolutionary psychology pays to literature is grouped into three areas, all addressed, albeit unequally, in The Literary Animal. The first is the evolutionary problem posed by the arts. The puzzle, as the book's editors Jonathan Gottschall and David Sloan Wilson, put it, is this: "In ancestral environments characterized by intense competition for survival and reproduction, how could the evolutionary process 'allow' any animal to spend (waste?) so much time producing, elaborating, and consuming art - time that could be spent pursuing mates and other quarry?"

An issue that divides evolutionary psychologists is whether the arts are adaptations to the biological exigencies of surviving and reproducing, or by-products of adaptations that evolved to perform other functions. This question attracts its fair share of debate in the book, with some contributors arguing vociferously for the 'art is adaptation' point of view, although each offers a different account of what the artistic adaptation is designed to do: perhaps increase our ability to sustain attention (Brian Boyd), or regulate "the human cognitive behavioural system" (Joseph Carroll). Michelle Scalise Sugiyama argues that the narrative arts have an adaptive purpose all of their own, unshared by the other art forms. The fact that narrative is set forth in language adapts it to be an "information storage and transmission system" that works by simulating - and stimulating - experience.

A second reason why evolutionary psychology pays attention to literature is as a source of evidence, buttressing its claims about human nature, including the claim that there is such a thing at all. The novelist Ian McEwan's contribution argues this claim: "It must be clear by now, I think, that the exercise of imagination and ingenuity as expressed in literature supports Darwin's view. It would not be possible to read and enjoy literature from a time remote from our own, or from a culture that was profoundly different from our own, unless we shared some common emotional ground, some deep reservoir of assumptions, with the writer."

Illustrating the search for literary data supporting the existence of a universal human nature are essays considering the importance of the male-male bond in epics and romances, the theme in both Japanese and Western literature of men rejecting children whom their wives have conceived in adultery, and a study that connects the two sorts of male hero presented in novels - the dark and dangerous Byronic 'cad', and the safe and reliable 'dad' - to female choices for short- and long-term pair bondings.

The third cluster of questions is the most tantalizing: can literary darwinism be transformed into a responsive literary theory that enhances our understanding and enjoyment of specific literary texts? A work of art, almost by definition, demands and rewards disciplined attention, and humanities scholars have long devoted themselves to techniques aimed at coaxing forth the full meaning of a work. The theories marshalled towards this end all have in common the claim that, despite the individual face that each work bears, there are general theoretical abstractions that can be applied to each that will reveal what is really going on within the text.

Although this third area seems closest to the meaning of the term 'literary darwinism', it receives the least attention in The Literary Animal. Only Carroll's chapter on "human nature and literary meaning" provides a close literary analysis of a specific text, Jane Austen's Pride and Prejudice. The result is certainly worthy; his reading of Austen is subtle and supple. But the depth of his analysis derives more from his purely literary observations on the multiplicity of points of view involved in literary works than from the general darwinian points he has to make.

It remains to be seen whether evolutionary psychology can spawn a true literary theory that helps us understand narrative in general why our species pays it so much attention, and how its universal themes reflect facets of human nature explained by evolutionary psychology and whether it will also yield a method subtle and flexible enough to deepen our understanding of specific literary works. In the meantime, The Literary Animal provides a fine example of the riches that await us as the arts and sciences stop competing and start communicating. Rebecca Goldstein is a philosopher and writer. Her most recent book is Betraying Spinoza: The Renegade Jew Who Gave Us Modernity. 